\title{
$n-3$ Fatty acid supplementation reduces hypertriacylglycerolaemia and improves lipid peroxidation and inflammation in patients with chronic renal failure
}

\author{
K. Mekki ${ }^{1}$, N. Bekada ${ }^{1}$, A. Boukaddoum ${ }^{1}$, D. Krouf ${ }^{1}$, A. Kaddous ${ }^{2}$ and M. Bouchenak ${ }^{1}$ \\ ${ }^{1}$ Laboratoire de Nutrition Clinique et Métabolique, Faculté des Sciences, Université d'Oran Es-Sénia, Oran, Algeria \\ and ${ }^{2}$ Service de Néphrologie, Centre Hospitalo-Universitaire d'Oran, Oran, Algeria
}

The aim of the present study was to evaluate the effect of $n-3$ fatty acid supplementation on dyslipidaemia, lipid peroxidation and inflammation markers in patients with chronic renal failure (CRF).

Seventy-five patients with CRF (58 (SD 9) years) were identified in the hospital in Oran (west Algeria). Thirty patients with hypertriacylglycerolaemia (TAG $>1.7 \mathrm{mmol} / \mathrm{l}$ ) and/or hypercholesterolaemia (total cholesterol (TC) $>5 \mathrm{mmol} / \mathrm{l}$ ) were recruited for the nutritional intervention. All patients received nutritional counselling adapted for CRF (energy intake $0.12 \mathrm{MJ} / \mathrm{kg}$ body weight per d, protein intake $0.8 \mathrm{~g} / \mathrm{kg}$ body weight per d, lipid intake $35 \%$ total energy intake). Fifteen patients received an $n-3$ fatty acid supplement ( $2.1 \mathrm{~g} / \mathrm{d}$; $33 \%$ EPA and $12 \%$ DHA) for 90 d. Fifteen patients were used as controls. Blood samples were withdrawn at the beginning (T0) and at $30 \mathrm{~d}(\mathrm{~T} 1), 60 \mathrm{~d}(\mathrm{~T} 2)$ and $90 \mathrm{~d}(\mathrm{~T} 3)$ after initiating treatment.

TAG level was reduced by $43 \%$ at T1, and decreased with time from T1 to T3. TC, HDL-cholesterol (HDL-C), LDL-cholesterol (LDL-C), apo A-I, apo B, TC:HDL-C, TC:LDL-C and apo A-I:apo B were similar for both groups, whereas apo B values were lower at T2 compared with T0 $(P<0.05)$. Decreases in TC:HDL-C and TC:LDL-C were found at T3 compared with T0 $(P<0.05)$. Thiobarbituric acid-reactive substances (TBARS) were lower in treated patients compared with controls $(P<0.001)$, and decreased with time from T1 to T3 $(P<0.001)$. Albumin concentrations were not affected by the nutritional intervention, whereas a significant reduction in $\mathrm{C}$-reactive protein (CRP) was found in treated patients compared with controls.

Table. Changes in some lipid variables, TBARS and inflammation markers

\begin{tabular}{|c|c|c|c|c|c|c|c|c|}
\hline & \multicolumn{2}{|c|}{ T0 } & \multicolumn{2}{|c|}{$\mathrm{T} 1$} & \multicolumn{2}{|c|}{$\mathrm{T} 2$} & \multicolumn{2}{|c|}{ T3 } \\
\hline & Mean & $\mathrm{SE}$ & Mean & $\mathrm{SE}$ & Mean & $\mathrm{SE}$ & Mean & $\mathrm{SE}$ \\
\hline $\mathrm{TAG}(\mathrm{mmol} / \mathrm{l})$ & 3.10 & 0.66 & $1.60 *$ & 0.56 & $1.55^{*}$ & 0.16 & $1.03 * *$ & 0.22 \\
\hline $\mathrm{TC}(\mathrm{mmol} / \mathrm{l})$ & 5.13 & 0.73 & 4.83 & 0.23 & 4.55 & 0.14 & $3.58 *$ & 0.12 \\
\hline TBARS $(\mathrm{mmol} / \mathrm{l})$ & 8.45 & 0.56 & $5.45 * * *$ & 0.14 & $2.37 * * *$ & 0.03 & $0.90^{* * *}$ & 0.07 \\
\hline Albumin (g/l) & 42.2 & 5.03 & 44.9 & 3.0 & 42.2 & 3.86 & 39.9 & 4.0 \\
\hline $\mathrm{CRP}(\mathrm{mg} / \mathrm{l})$ & \multicolumn{2}{|c|}{$<6$} & \multicolumn{2}{|c|}{$<1.5$} & \multicolumn{2}{|c|}{$<1.5$} & \multicolumn{2}{|c|}{$<1.5$} \\
\hline
\end{tabular}

Mean values were significantly different from those at T0: $* P<0.05, * * P<0.01, * * * P<0.001$.

In patients with CRF $n-3$ PUFA supplementation reduces hypertriacylglycerolaemia and improves lipid peroxidation and inflammation and can be beneficial in the prevention of CVD. 